\title{
Acute otitis media: a new treatment strategy
}

\author{
F L VAN BUCHEM, M F PEETERS, M A VAN 'T HOF
}

\begin{abstract}
The incidence of acute otitis media and its response to treatment only with nose drops and analgesics (but without antibiotics or myringotomy) were assessed over three months by 45 doctors in and around Tilburg. In addition, over 17 months 60 general practitioners assessed the effects of this limited treatment in children aged 2 to 12 years and referred all those in whom the condition took an unsatisfactory course (either a severe course-illness continuing beyond three to four days with high temperature or pain, or both-or persistent discharge after 14 days) to an ear, nose, and throat specialist. Those referred because of appreciable illness continuing beyond three or four days were entered into a further study, comparing the effects of myringotomy alone, antibiotics alone, and myringotomy and antibiotics combined. Bacteriology was assessed in all children in whom the course of the condition was unsatisfactory.

More than $90 \%$ of an estimated 4860 children seen over 17 months (estimation based on incidence of severe course in the three month study) recovered within a few days. The course of the condition was severe in only 126 $(2.7 \%)$ patients; haemolytic streptococci group A were identified in 30 of these 126 patients but Haemophilus influenzae in only one. One hundred of these patients with a severe course entered the trial of treatment, which showed antimicrobial treatment either alone or in combination to be more effective than myringotomy alone. Whether combined treatment was more effective than antibiotics alone remained unconfirmed.

Acute otitis media in children can be treated with nose drops and analgesics alone for the first three to
\end{abstract}

St Elisabeth Hospital, Tilburg, The Netherlands

F L VAN BUCHEM, MD, ear, nose, and throat department

$M$ F PEETERS, MD, regional public health laboratory

Department of Statistical Consultation, University of Nijmegen, The Netherlands

M A VAN 'T HOF, statistician

Correspondence to: Dr F L van Buchem. four days. Patients in whom this regimen is not accompanied by satisfactory recovery can be recognised within a short time and treated by the general practitioner.

\section{Introduction}

In a previous study we found that most children treated for acute otitis media with nose drops and analgesics alone-that is, without myringotomy or antibiotics-recovered quickly and that the course of the condition was unsatisfactory in only a small proportion of patients, who could be divided into two groups: those in whom the course of the condition was severe (still ill after three to four days, with persistent high temperature or severe pain, or both) and those with persistent discharge after 14 days. ${ }^{1}$ We now report a large scale medical audit of this limited treatment of acute otitis media and describe our findings in the patients in whom the treatment was unsatisfactory.

\section{Patients and methods}

For 17 months (1 March 1981 to 1 August 1982) 60 general practitioners in and around Tilburg (total population at risk 155000 ) treated all patients aged 2 years or more suffering from acute otitis media with nose drops and analgesics alone. Patients with a concurrent infection requiring antibiotics were excluded. The diagnosis of acute otitis media was based on history, clinical findings, and, as the conclusive factor, the condition of the tympanic membrane (diffusely red or bulging, or both).

All patients in whom the condition took an unsatisfactory course were referred to one of three ear, nose, and throat specialists (two in an associate practice, one in a solo practice). They were grouped according to whether the course of the condition was severe (still ill after three to four days, with persistent high temperature or severe pain, or both) or discharge persisted for more than 14 days and, if aged 2 to 12 , were entered into a further study.

The 17 month study was carried out in general practices of five to 12 doctors, one of whom liaised with the organising ear, nose, and throat specialist (FLVB), ensuring direct contact between the participating physicians.

We also wished to gain an impression of the total number of patients with otitis media in the area. From February to April 1982, 45 general practitioners registered all their patients with the condition and indicated those in whom the course was severe, those in whom discharge persisted beyond 14 days, and those who received antibiotics for a concurrent condition. 
The results of the 17 month study were compared with the findings of these 45 general practitioners and epidemiological data on otitis media in the Netherlands. ${ }^{2}$

\section{SEVERE CASES}

The ear, nose, and throat specialists to whom patients with a severe course of otitis media were referred studied the bacteriology, virology, and effects of different treatments (myringotomy or antibiotics, or both) in patients aged 2 to 12 years. Patients were excluded from the trial if they had been receiving antibiotics one month or less before the trial, were allergic to the antibiotic used in the trial (amoxycillin), or had a history of chronic otitis media or otitis media serosa

At the child's first visit the ear, nose, and throat specialist asked about: the duration of symptoms; the duration of treatment by the general practitioner; any history of otitis media; any history of adenoidectomy or tonsillectomy, or both; and any history of frequent or rare episodes of rhinitis. He examined the tympanic membrane and recorded the degree of pain, the degree of illness, and the temperature. Bacterial cultures were started and a blood sample obtained for examination of viral serology.

On the second day the same specialist, or his associate, asked about pain, discharge, degree of illness, and temperature. On the seventh these questions were repeated but the temperature was measured only if it had been above $38^{\circ} \mathrm{C}$ on the second day. Degree of discharge and condition of the tympanic membrane were recorded. This was repeated on the 14th day, and another sample of blood was taken for determining viral serology after two to three weeks.

After one, two, and six months the ears were reinspected and questions asked about recurrence.

Treatment-Patients were randomly assigned to receive myringotomy, antibiotics, or a combination of the two. Those not receiving myringotomy underwent sham myringotomy (touching the auditory canal with a needle) to preserve the double blind design of the trial. Both operations were performed under local anaesthesia with a lignocaine (Xylocaine) spray. The antibiotic used was amoxycillin (Clamoxyl), $250 \mathrm{mg}$ in sachets thrice daily for seven days. The placebo used looked and tasted the same as the antibiotic. Patients were randomly assigned to treatment from a computer list, the practice nurse informing the ear, nose, and throat specialist of the treatment that applied in each case. The specialist who saw the patient on the first day knew which treatment was started, but neither the child nor the parent did. Subsequently, children attending the associate ear, nose, and throat practice saw the other specialist, who did not know which treatment had been started. On the second day the tympanic membrane was not examined and treatment was recorded separately and remained unknown to the specialist. A double blind design was not, however, fully achieved because in the solo practice the ear, nose, and throat specialist was aware of the treatment started. This affected six patients.

Statistical analysis-The overall effect of the different treatments was evaluated by one way analysis of variance, or the $\chi^{2}$ test in the case of nominal data. If such an overall test gave a significant difference between the treatments the difference was further explored using Student's $t$ test or the $\chi^{2}$ test. For these tests a nominal significance level of $\alpha=0.02$ was used to ensure a real significance level of 0.05 .

Change of treatment during the trial-If the clinical course continued to be unsatisfactory (persistent illness with intense pain or high temperature, or both) the treatment was changed. Those assigned to treatment with myringotomy alone were given amoxycillin, and those receiving amoxycillin alone were treated also by myringotomy. In patients already receiving amoxycillin and myringotomy antibiotic treatment was continued with a different compound chosen on the basis of the results of bacterial culture.

Assessment-The tympanic membrane was assessed as normal, diffusely red, bulging, or perforated. The mother was asked about the severity of pain, which was then recorded as intense, present, or absent. The temperature was measured rectally by the specialist's practice nurse on the first day and by the mother on the second and, if necessary, seventh days. Discharge was recorded as much, moderate, or absent. Reappearance of otitis after an asymptomatic period of at least two weeks was recorded as recurrence.

Bacteriological tests-Material for these was obtained from the ear with disposable sterile loops (NUNC $1 \mu$ l loops N-1001-2; NUNC, Roskilde, Denmark) and immediately inoculated in a solid nutrient medium (heart infusion agar with $10 \%$ fresh oxalate sheep blood added) on two plates. Immediately after inoculation the mediums were brought to the laboratory for medical microbiological investigation and incubated at $37^{\circ} \mathrm{C}$ for 48 hours, with one plate of mediumw under aerobic and the other under anaerobic conditions. That incubated under aerobic conditions was inoculated with a streak of Staphylococcus aureus to permit the growth of Haemophilus influenzae (satellite effect).

Virological tests-One serum sample taken at the acute phase of illness and another taken two to three weeks later were tested for possible virus infections with the complement fixation reaction using a microtechnique and also with a haemagglutination inhibition reac- $\infty$ tion for influenza and parainfluenza viruses. A fourfold or greater rise in titre was accepted as proof of a previous infection. Testing was. done for: adenovirus, respiratory syncytial virus, corona virus, influenza $\mathrm{A}, \mathrm{B}$, and $\mathrm{C}$ viruses, parainfluenza 1,2 , and 3 viruses, mumps virus, and herpes simplex virus.

Tests for micro-organisms-In addition, serological tests wereo performed to identify micro-organisms not regarded as viruses but causing respiratory infections, such as Mycoplasma pneumoniae,, $\mathbb{\Phi}$ Coxiella burnetti ( $Q$ fever), and Chlamydia psittaci (psittacosis).

We did not attempt to isolate viruses from the middle ear in viewos of the disappointing results of others ${ }^{3-5}$ and because serological $\vec{\circ}$ methods are generally more sensitive than culture methods in detecting infection with the viruses listed above. ${ }^{6}$

\section{PATIENTS WITH PERSISTENT DISCHARGE}

All patients with discharge persisting for more than 14 days aftero the onset of acute otitis media were referred to ear, nose, and throat specialists. Samples for bacteriological culture were obtained and ${ }^{+}$ tympanic membranes examined. All those aged 2 to 12 were treated $\overrightarrow{0}$ with amoxycillin and re-examined after 14 days.

\section{Results}

Table I shows the numbers of patients with acute otitis media seen over three months by 45 general practitioners (a total of 9.25 practice years). Of 490 children seen aged 2 to 12 years, $13(2 \cdot 7 \%)$ developedoo a severe course of the condition. During the 17 month study $126^{\mathrm{G}}$ children were seen in whom the course was severe. Assuming that the incidence of $2.7 \%$ for the severe course in the three month study was the same in the 17 month study, we estimate (table I) that over the 17 months there were 6900 patients with acute otitis media, including 4860 children. These figures correspond with epidemiologica $\bar{D}$ data on otitis media in the Netherlands $(81.6$ patients per genera practice per year; during 17 months in 60 general practices this $\overrightarrow{\widehat{O}}$ would give 6900 patients). ${ }^{2}$

TABLE I-Number of patients with acute otitis media treated with nose drops

\begin{tabular}{|c|c|c|}
\hline Patients with otitis media & Three month study & 17 month study \\
\hline $\begin{array}{l}\text { Total No } \\
\text { No aged } 2-12 \text { years } \\
\text { No }(\%) \text { excluded by family doctor* } \\
\text { No }(\%+) \text { cured } \\
\text { No }(\%+) \text { with severe course } \\
\text { No }(\%+) \text { with discharge after } 14 \text { days } \\
\text { No }(\%+) \text { excluded } \\
\text { No }(\%+) \text { with mastoiditis }\end{array}$ & $\begin{array}{l}709 \\
490 \\
22(4 \cdot 5) \\
445(95) \\
13(2 \cdot 7) \\
7(1 \cdot 5) \\
3(0 \cdot 6)\end{array}$ & $\begin{aligned} 6900 \S & \\
4860 \S & \$(4 \cdot 5) \\
220 \S( & 4000 \S(>90) \\
126 & (2 \cdot 7) \\
& \\
2 & (0 \cdot 04)\end{aligned}$ \\
\hline
\end{tabular}

* Given antibiotic for concurrent infection

+Proportion of all children with acute otitis media except those given antibiotic $N$

$\ddagger$ for a concurrent infection. agreed programme.

\section{SEVERE CASES}

The condition took a severe course in 126 patients aged 2 to 12 years. Twenty six of these were excluded from the study because of $\Omega$ mastoiditis at first visit (one); allergy to amoxycillin (one); anti- 2 biotics given for otitis media within one month before (eight); noo cooperation or lack of sufficient data (16). Of the 100 remaining children (nine aged 2 years ; eight, $3 ; 16,4 ; 18,5 ; 16,6 ; 10,7 ;$ five, 8 응 seven, 9 ; four, 10 ; four, 11 ; and three, 12), 34 were assigned to receive myringotomy alone, 30 to receive antibiotics alone, and 36 myrin gotomy and antibiotics combined. 
Statistical analysis of the data showed that the patients in the three treatment groups were fairly well matched: no significant differences were found in age, history of rhinitis, duration of acute otitis media before the first visit to the ear, nose, and throat specialist (mean 4.8 days), duration of treatment for otitis by family doctor (mean 3.6 days), temperature at first examination, or condition of the tympanic membrane using one way analysis of variance; or in sex history of adenoidectomy or tonsillectomy, ear, nose, and throa specialist attendance, or incidence of unilateral or bilateral infection using the $\chi^{2}$ test. brane returned to normal less quickly after treatment with myringotomy alone than after treatment with amoxycillin and myringotomy combined. The group given amoxycillin alone and that treated by myringotomy and amoxycillin showed an equally rapid return to normal.

Discharge (table IV) was significantly less in patients treated with myringotomy and amoxycillin than in those treated with myringotomy alone ( $p<0.001$ after seven days; $p<0.01$ after 14 days).

Clinical course-The patients receiving myringotomy alone were significantly less well, as assessed by parents, on the second day than

TABLE II-Duration of pain in patients treated for a severe course of acute otitis media with myringotomy alone (group 1), antibiotics alone (group 2), or myringotomy and antibiotics (group 3). Figures indicate numbers of patients

\begin{tabular}{|c|c|c|c|c|c|c|c|c|c|}
\hline \multirow{2}{*}{ Pain } & \multicolumn{3}{|c|}{ First visit } & \multicolumn{3}{|c|}{ After 24 hours } & \multicolumn{3}{|c|}{ After seven days } \\
\hline & Group 1 & Group 2 & Group 3 & Group 1 & Group 2 & Group 3 & Group 1 & Group 2 & Group 3 \\
\hline $\begin{array}{l}\text { None } \\
\text { Moderate } \\
\text { Severe }\end{array}$ & $\begin{array}{r}2 \\
2 \\
30\end{array}$ & $\begin{array}{r}3 \\
8 \\
18\end{array}$ & $\begin{array}{r}2 \\
9 \\
25\end{array}$ & $\begin{array}{r}17 \\
3 \\
7\end{array}$ & $\begin{array}{r}16 \\
7 \\
1\end{array}$ & $\begin{array}{r}23 \\
5 \\
3\end{array}$ & $\begin{array}{r}24 \\
2\end{array}$ & $\begin{array}{r}26 \\
3\end{array}$ & $\begin{array}{r}34 \\
1\end{array}$ \\
\hline Total & 34 & 29 & 36 & 27 & 24 & 31 & 26 & 29 & 35 \\
\hline
\end{tabular}

TABLE III-Otoscopic findings on three occasions in patients treated for a severe course of acute otitis media with myringotomy alone (group 1), antibiotics alone (group 2), or myringotomy and antibiotics (group 3). Figures indicate numbers of patients

\begin{tabular}{|c|c|c|c|c|c|c|c|c|c|}
\hline \multirow{2}{*}{ Tympanic membrane } & \multicolumn{3}{|c|}{ First visit } & \multicolumn{3}{|c|}{ After seven days } & \multicolumn{3}{|c|}{ After 14 days } \\
\hline & Group 1 & Group 2 & Group 3 & Group 1 & Group 2 & Group 3 & Group 1 & Group 2 & Group 3 \\
\hline \multirow{2}{*}{$\begin{array}{l}\text { Normal } \\
\text { Thick, reddened } \\
\text { Bulging } \\
\text { Perforated }\end{array}$} & \multirow{2}{*}{$\begin{array}{r}6 \\
25 \\
3\end{array}$} & \multirow[t]{2}{*}{$\begin{array}{r}5 \\
25\end{array}$} & \multirow{2}{*}{$\begin{array}{r}2 \\
31 \\
3\end{array}$} & \multirow{2}{*}{$\begin{array}{r}8 \\
6 \\
1 \\
11\end{array}$} & $\begin{array}{r}22 \\
5\end{array}$ & $\begin{array}{r}21 \\
7\end{array}$ & $\begin{array}{r}20 \\
1\end{array}$ & $\begin{array}{r}23 \\
2\end{array}$ & $\begin{array}{r}30 \\
1\end{array}$ \\
\hline & & & & & 1 & 7 & 6 & 1 & 1 \\
\hline Total & 34 & 30 & 36 & 26 & 28 & 35 & 27 & 26 & 32 \\
\hline
\end{tabular}

TABLE IV-Duration of discharge in patients treated for a severe course of acute otitis media with myringotomy alone (group 1), antibiotics alone (group 2), or myringotomy and antibiotics (group 3). Figures indicate numbers of patients

\begin{tabular}{|c|c|c|c|c|c|c|c|c|c|}
\hline \multirow{2}{*}{ Discharge } & \multicolumn{3}{|c|}{ After 24 hours } & \multicolumn{3}{|c|}{ After seven days } & \multicolumn{3}{|c|}{ After 14 days } \\
\hline & Group 1 & Group 2 & Group 3 & Group 1 & Group 2 & Group 3 & Group 1 & Group 2 & Group 3 \\
\hline $\begin{array}{l}\text { None } \\
\text { Moderate } \\
\text { Considerable }\end{array}$ & $\begin{array}{r}5 \\
2 \\
22\end{array}$ & $\begin{array}{r}21 \\
1 \\
2\end{array}$ & $\begin{array}{r}8 \\
9 \\
15\end{array}$ & $\begin{array}{r}15 \\
3 \\
8\end{array}$ & $\begin{array}{r}27 \\
1\end{array}$ & $\begin{array}{r}30 \\
4 \\
1\end{array}$ & $\begin{array}{r}20 \\
2 \\
5\end{array}$ & $\begin{array}{r}25 \\
1\end{array}$ & $\begin{array}{r}31 \\
1\end{array}$ \\
\hline Total & 29 & 24 & 32 & 26 & 28 & 35 & 27 & 26 & 32 \\
\hline
\end{tabular}

TABLE V-Clinical course in children treated for a severe course of acute otitis media with myringotomy alone (group 1), antibiotics alone (group 2), or myringotomy and antibiotics (group 3). Figures indicate numbers of patients

\begin{tabular}{|c|c|c|c|c|c|c|c|c|c|}
\hline \multirow{2}{*}{ Clinical course } & \multicolumn{3}{|c|}{ First visit } & \multicolumn{3}{|c|}{ After 24 hours } & \multicolumn{3}{|c|}{ After seven days } \\
\hline & Group 1 & Group 2 & Group 3 & Group 1 & Group 2 & Group 3 & Group 1 & Group 2 & Group 3 \\
\hline $\begin{array}{l}\text { Satisfactory } \\
\text { Moderate } \\
\text { Unsatisfactory }\end{array}$ & $\begin{array}{r}6 \\
19 \\
7\end{array}$ & $\begin{array}{r}8 \\
16 \\
6\end{array}$ & $\begin{array}{r}11 \\
17 \\
8\end{array}$ & $\begin{array}{r}11 \\
13 \\
4\end{array}$ & $\begin{array}{r}18 \\
7\end{array}$ & $\begin{array}{r}24 \\
7\end{array}$ & $\begin{array}{r}24 \\
3\end{array}$ & 28 & $\begin{array}{r}34 \\
1\end{array}$ \\
\hline Total & 32 & 30 & 36 & 28 & 25 & 31 & $27^{*}$ & 28 & 35 \\
\hline
\end{tabular}

*Excludes four patients meanwhile also treated with amoxycillin.

The group receiving combined treatment turned out to include six of seven patients with a history of five or more episodes of acute otitis media. These patients were not excluded from the trial because their clinical course did not differ from that in other patients.

Temperature-The mean (SD) temperature of the 100 patients on the first day $(38.0(0.9) \mathrm{C})$ was higher than that reported by us in our previous study $\left(37.6(0.9){ }^{\circ} \mathrm{C}\right),{ }^{1}$ as could be expected in view of our preselection of patients. The fall in temperature on the second day was significantly smaller in patients treated by myringotomy (to $\left.37.4(0.7)^{\circ} \mathrm{C}\right)$ than in those treated with amoxycillin and myringotomy (to $\left.37 \cdot 1(0.7)^{\circ} \mathrm{C}\right)(\mathrm{p}<0.05 ;$ Student's $t$ test).

Pain-Table II shows duration of pain for the different treatment groups. Pain after 24 hours had not responded better to myringotomy than to amoxycillin ( $\mathrm{p}>0.05$; Student's $t$ test).

Otoscopic findings-Table III shows otoscopic findings in patients in the three treatment groups. The condition of the tympanic mem- those given amoxycillin instead $(p<0.004)$ or as well $(p<0.005)$ (table $\mathrm{V}$ ). In the course of the following days four patients treated with myringotomy alone were also given amoxycillin because the clinical course continued to be unsatisfactory; one of these patients had developed mastoiditis.

Recurrence was no more common in patients given amoxycillin than in those treated with myringotomy alone. The power of the trial was not, however, sufficiently great to be sure that (on a large scale) no differences in recurrence could exist.

Table VI shows the results of the statistical analysis.

Complications-Two patients developed mastoiditis. One was not included in the trial because mastoiditis was noted at the first visit; he was immediately given amoxycillin and submitted to myringotomy. The other patient showed mastoiditis on the seventh day after first presentation. He was among the above mentioned four patients assigned to treatment with myringotomy alone who showed a per- 
TABLE VI-Statistical analysis, according to different variables, of the effects of myringotomy alone (group 1), antibiotics alone (group 2), and myringotomy and antibiotics (group 3) in severe cases of acute otitis media

\begin{tabular}{|c|c|c|c|c|}
\hline \multirow[b]{2}{*}{ Variable } & \multirow{2}{*}{$\begin{array}{c}\text { No of } \\
\text { days } \\
\text { after } \\
\text { treatment }\end{array}$} & \multicolumn{3}{|c|}{ p values* } \\
\hline & & $\begin{array}{l}\text { Group } 1 v \\
\text { Group } 2\end{array}$ & $\begin{array}{l}\text { Group } 1 v \\
\text { Group } 3\end{array}$ & $\begin{array}{l}\text { Group } 2 v \\
\text { Group } 3\end{array}$ \\
\hline $\begin{array}{l}\text { Temperature } \\
\text { Decrease in temperature }\end{array}$ & 2 & $\begin{array}{l}0.04^{+} \\
\text {NS }\end{array}$ & $\begin{array}{l}\text { NS } \\
0.05\end{array}$ & NS \\
\hline Pain & $\left\{\begin{array}{r}2 \\
7 \\
14\end{array}\right.$ & $\begin{array}{l}\text { NS } \\
\text { NS } \\
\text { NS }\end{array}$ & $\begin{array}{l}\text { NS } \\
\text { NS } \\
\text { NS }\end{array}$ & $\begin{array}{l}\text { NS } \\
\text { NS } \\
\text { NS }\end{array}$ \\
\hline Otoscopic findings & $\left\{\begin{array}{r}7 \\
14\end{array}\right.$ & $\begin{array}{l}0.0001 \S \\
0.04 \S\end{array}$ & $\begin{array}{l}0.008_{+}^{+} \\
0.02_{+}^{+}\end{array}$ & NS \\
\hline Discharge & $\left\{\begin{array}{r}2 \\
7 \\
14\end{array}\right.$ & $\begin{array}{l}0.001 \S \\
0.0002 \S \\
0.04 \S\end{array}$ & $\begin{array}{l}\text { NS } \\
0.0011_{+}^{+} \\
0.01_{+}^{+}\end{array}$ & $\begin{array}{l}0.0001 \S \\
\text { NS } \\
\text { NS }\end{array}$ \\
\hline $\begin{array}{l}\text { Clinical course } \\
\text { Recurrence }\end{array}$ & $\begin{array}{r}2 \\
40\end{array}$ & $\begin{array}{l}0.004^{+} \\
\text {NS }\end{array}$ & $\begin{array}{l}0.0005_{+}^{+} \\
0.022_{+}^{+}\end{array}$ & NS \\
\hline
\end{tabular}

NS $=$ not significant $(p>0.05)$

*Student's $t$ test or $\chi^{2}$ test, depending on circumstances.

+Myringotomy less effective than amoxycillin.

speak and amoxycillin more efrective than myringotomy alone.

$\S$ Strictly speaking not relevant because data are a direct consequence of myringotomy

sistently unsatisfactory clinical course. He was given amoxycillin in addition. Both patients made an uneventful recovery.

Exclusion during the trial-One patient was removed from the trial because his family doctor had prescribed antibiotics contrary to the agreed programme. Another (assigned to treatment with myringotomy alone) developed contralateral otitis media after one week.

Bacteriological and virological findings-Bacteriological examination of the middle ear was possible in the 70 patients treated by myringotomy. In the 30 not so treated a smear was taken from the tympanic membrane and examined bacteriologically. Table VII shows the results. Virological tests were performed in 60 patients (table VIII). In $15(25 \%)$ a virus infection was shown by a more than fourfold rise in titre. In the $\mathbf{4 0}$ remaining patients no paired serum samples were available for serological testing.

\section{PATIENTS WITH PERSISTENT DISCHARGE}

Altogether about 70 patients were referred for persistent discharge after 14 days. We examined the first 29. All perforations proved to be central and all except one closed after treatment with

TABLE VII-Bacteria cultured from ear secretions of patients in whom acute otitis media took a severe course

\begin{tabular}{lcc}
\hline \multirow{2}{*}{ Micro-organism } & \multicolumn{2}{c}{ No $(\%)$ of patients: } \\
\cline { 2 - 3 } & $\begin{array}{c}\text { Treated by } \\
\text { myringotomy } \\
(\mathrm{n}=70)\end{array}$ & $\begin{array}{c}\text { Not treated by } \\
\text { myringotomy } \\
(\mathrm{n}=30)\end{array}$ \\
\hline B Haemolytic streptococci group A & $27(39)$ & $3(10)$ \\
Streptococcus pneumoniae & $12(17)$ & $1(3 \cdot 3)$ \\
Haemophilus influenzae & $1(1 \cdot 4)$ & 0 \\
Staphylococcus aureus & $5(7)$ & $1(3 \cdot 3)$ \\
Enterobacteriaceae and pseudomonas & $0(26)$ & $2(6 \cdot 7)$ \\
Sterile or apathogenic micro-organisms & $18(26)$ & $21(70)$ \\
Unknown & $7(10)$ & $2(6 \cdot 7)$ \\
\hline
\end{tabular}

TABLE VIII-Respiratory viral infections associated with acute otitis media in 60 patients in whom acute otitis media took a severe course, according to age in years

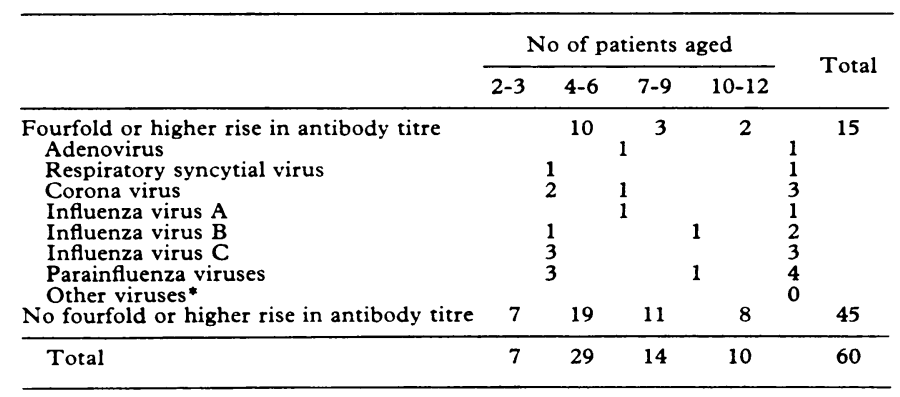

*Mumps virus and herpes simplex virus as well as Mycoplasma pneumoniae, Coxiella Mumps virus and herpes simplex
burneti, and Chlamydia psittaci. antibiotics; haemolytic streptococci were found most often, only one patient giving a pure culture of $H$ influenzae (table IX). In one patient the affected ear was still not dry after two weeks; pseudomonas was cultured. In another case the paediatrician prescribed ery thromycin against bronchitis while treatment with amoxycillin wab still in progress.

TABLE IX-Patients with discharge after 14 days: bacteria cultured on the first day from 33 middle ears of 29 patients

\begin{tabular}{lc}
\hline \multicolumn{1}{c}{ Micro-organism } & No of middle ears \\
\hline Haemolytic streptococci & 9 \\
Pneumococci & 2 \\
Haemophilus influenzae & 1 \\
Staphylococcus aureus & 7 \\
Escherichia coli & 1 \\
Pseudomonas & 1 \\
Haemolytic streptococci and pseudomonas & 5 \\
Haemolytic streptococci and Staphylococcus aureus & 2 \\
Haemophilus influenzae and pneumococi & 1 \\
Haemophilus influenzae and pseudomonas & 3 \\
Sterile cultures & \\
\hline
\end{tabular}

ACCEPTANCE OF TREATMENT BY PARENTS AND GENERAL PRACTITIONERS

Myringotomy is the usual treatment for acute otitis media in the Netherlands, but since our previous study ${ }^{1}$ we have been prepared to abandon it. Omission of antimicrobial treatment did not raise any protest as in the Netherlands antibiotics are not usually prescribeds for this condition. During the study both parents and general prac $\not$ titioners were astonished that so many children recovered so fast when treated with nose drops and analgesics alone.

The number of audiograms made was unfortunately too small tơ obtain useful data.

\section{Discussion}

In over $90 \%$ of an estimated 4860 children with acute otitisొ media simple treatment with nose drops and analgesics ensured a cure within a few days. The condition took a severe course (persistent illness with severe pain or high temperature, of both, after three to four days) in only 126 (less than 3\%), and discharge continued for more than 14 days in another $2 \% \%$ The general practitioner decided whether children needed $P$ antibiotics for a concurrent condition. We assume that this group nevertheless included children given antibiotics for acute otitis media rather than some other condition. Even if this entire group of children (roughly $220(4.5 \%)$ ) is included? however, fewer than $10 \%$ of all patients with acute otitis medias aged 2 to 12 required supplementary treatment.

When treating acute otitis media general practitioners shouldo be able, easily and in time, to determine which cases are likelye. to have an unsatisfactory course. In this study we were able to do this not only in patients with persistent discharge but also in those with a severe course of the condition. It is also importanto that parents receive proper instructions. Another finding of this study, in relation to what treatment should be given in un-O satisfactory cases, was the good response of both groups of patients to antimicrobial treatment. Duration of discharge restoration of the tympanic membrane, and clinical course were all appreciably less satisfactory in patients treated with myringotomy alone. Our data do not, however, warrant the conclusion that myringotomy and antibiotics combined giveo better results than antibiotics alone.

Bacteriological studies in patients with a severe clinical course showed haemolytic streptococci in 30 but $\mathrm{H}$ influenzae in only one. Unfortunately, we have no microbial data from our previous study. ${ }^{1}$ Nevertheless, the single isolation of $H$ influenzae and? common isolations of haemolytic streptococci were very likely due to the particular characteristics of the patients with ano unsatisfactory course included in this study. This would correlate with data recorded by Lahikainen ${ }^{7}$ and Howie et al, 8 which also indicated that infection with $H$ influenzae is likely to cause less pain and to disappear quickly and spontaneously 
Our findings fail to show with any certainty whether viruses play a part in the pathogenesis of acute otitis media. An appreciable rise in titre to antibodies against a respiratory virus was found in $15(25 \%)$ of the 60 patients tested: four had received antibiotics alone and 11 myringotomy alone or in combination. Pathogenic bacteria were isolated from the middle ear in six of these 11 patients.

Complications developed in few cases. The two patients with mastoiditis, who also were identified easily, responded well to amoxycillin. Regardless of the type of treatment, the incidence of mastoiditis has decreased greatly over the past few decades; before 1946 the incidence in patients with otitis was $10-44 \%$; in 1954 Rudberg could still report an incidence of $17 \% .^{9}$ The use of antibiotics in all cases of otitis cannot be the cause of this considerable decrease; if it were the decrease would have been less pronounced in the Netherlands, where myringotomy without an antibiotic has been the common treatment. Moreover, mastoiditis would have developed in more patients during our trial. In the Netherlands antibiotics are likely to be used when otitis takes an unsatisfactory course despite myringotomy. Our patients with a severe course or with persistent discharge after 14 days may have included patients susceptible to mastoiditis in whom antibiotics prevented this complication. Thus antibiotic treatment in this selective group may have contributed to a reduction in the incidence of mastoiditis; this does not, however, explain the difference in incidence between the 1940s and the past decade. The conclusion therefore seems justified that both the decrease in the incidence of mastoiditis and the surprisingly favourable course of acute otitis media treated with nose drops and analgesics alone can be explained by changes in the clinical features of this condition.

In conclusion, treatment of acute otitis media in children can be limited to nose drops and analgesics for the first three to four days. An antibiotic, preferably a penicillin, can be given in the severe cases (still ill after three to four days with persistent high temperature or severe pain, or both) and to patients who do not clinically appear to be ill but still have discharge of the ear after two weeks. Should this treatment not lead to clinical improvement within a few days, further antibiotic treatment should be determined on the basis of a culture. Parents must be instructed to return to the general practitioner if the clinical course is unsatisfactory. If this decision cannot be left to the parents the general practitioner should make a further visit obligatory.

This study was made possible by the cooperation and help of general practitioners in and around Tilburg. We thank them and, in particular, M A M Boormans, $M$ Th M Cottaar, H Dunk, F J H M de Groot, P C G Haenen, J Hilbink, L H M Marres, B Schräder, P P Taminiau, and $W$ Wouts, who acted as liaison officers. We also thank Professor F J A Huygen, Institute for General Practitioners, University of Nijmegen; Professor F Sturmans, departments of social medical science, universities of Nijmegen and Maastricht; and Professor W Kuypers, ear, nose, and throat department, Nijmegen University Hospital, for their encouragement; and our colleagues Dr H Festen and Dr J J W Roovers for their selfless help.

\section{References}

1 van Buchem FL, Dunk JHM, van 't Hof MA. Therapy of acute otitis media: myringotomy, antibiotics or

epidemiologie van het Nilles JG, Kussartseninstituut. Nijmegen: Nijmeegs Huisartseninstituut, 1980 . studies and attempts to isolate viruses and mycoplasmas from aspirated middle ear fluids. N Engl f Med 1967;277:613-8.

Klein JO, Teele DW. Isolation of viruses and mycoplasmas from middle ear effusions: a review. Ann Otol Rhinol Laryngol 1976;85:140-4.

Adlington $P$, Hooper WK. Virus studies in secretory otitis media. $\mathcal{f}$ Laryngol Otol 1980;94:191-6.

Lennette EH, Schmidt NJ. Diagnostic procedures for viral, rickettsial and chlamydial infections. 5th ed. Washington: American Public Health Association, 1979 . the tympanum as a diagnostic and therapeutic method. Acta Otolaryngol the tympanum as a diagnostic
[Suppi] (Stockh) $1954 ; 107: 1-82$.

8 Howie VM, Ploussard JH, Lester RL Jr. Otitis media : a clinical and bacteriological correlation. Pediatrics 1970;45:29-35. Rudberg RD. Acute otitis media. Acta Otolaryngol [Suppl] (Stockh) 1954;113
1-69.

(Accepted 4 December 1984)

\title{
Relation between recurrence of cancer of the colon and blood transfusion
}

\author{
NEIL BLUMBERG, MUKESH M AGARWAL，CHRISTY CHUANG
}

\begin{abstract}
Data suggest that blood transfusion can cause immunosuppression. The incidence of recurrence of tumours was examined retrospectively in patients who had undergone potentially curative operations for cancer of the colon during 1970-81. Tumours recurred in six of 68 patients $(9 \%)$ who had not been given transfusions and in 56 of 129 patients $(43 \%)$ who had $(p \ll 0.0001)$. Transfusion was also found to be significantly associated with the time to
\end{abstract}

\footnotetext{
Department of Pathology and Laboratory Medicine and Division of Biostatistics, University of Rochester Medical Center, Rochester, New York 14642, USA

NEIL BLUMBERG, MD, associate professor of pathology and laboratory medicine

MUKESH M AGARWAL, MD

CHRISTY CHUANG, PHD

Correspondence to: Professor Neil Blumberg.
}

recurrence after adjustment for other baseline prognostic factors $(\mathbf{p}<0.05)$.

Perioperative transfusion may be a significant risk factor in the prognosis of cancer of the colon. Whether this association is causal is unknown.

\section{Introduction}

Recent clinical and laboratory data obtained in animals agree with the hypothesis that homologous blood transfusion decreases immune responsiveness. ${ }^{1}$ Animal and human recipients of renal transplants have a lower incidence of rejection of the graft if they have previously received blood transfusion. ${ }^{2}{ }^{3}$ Growth of tumours in animals that have received transfusions may be more rapid than in those that have not. ${ }^{5}$ Preliminary data indicate that patients with cancer of the colon who receive blood transfusions have an increased incidence of recurrence of cancer. ${ }^{6}$ We performed a retrospective analysis of transfusions and recurrence in patients with surgically curable cancer of the colon to confirm or refute this initial report. 